\title{
The Influence of Neuroticism on the Muscle Response in the Trapezius and Frontalis Muscles to Anticipatory Stress
}

\author{
Florestan Wagenblast, Robert Seibt, Thomas Läubli, Monika A. Rieger, \\ and Benjamin Steinhilber
}

Institute of Occupational and Social Medicine and Health Services Research, University Hospital Tübingen, University of Tübingen, Germany

\begin{abstract}
Objective quantification of mental stress in the workplace would be beneficial for designing work tasks to avoid the negative consequences of mental stress. Methods such as surface electromyography have proven to be sensitive to mental demands. However, there is little knowledge about the muscle response and moderating factors during anticipatory stress paradigms. This study examined whether the personality dimension neuroticism moderates the muscle response to the expectation of an unpredictable electrical shock. Forty-seven subjects underwent three expectation phases, in which they could expect a pleasant audio signal (NoShock) or an electric shock in two conditions (anticipation of the first: Shock1, and second electric shock: Shock2) at an unpredictable moment. The frontalis muscle activity and the upper and upper/middle parts of the trapezius muscle were recorded using surface electromyography. Neuroticism was surveyed using the Big Five Inventory to assign the subjects to a group with lower or higher neuroticism. Shock1 only induced higher trapezius muscle activity in the higher neuroticism group, which vanished during Shock2, while the frontalis muscle showed no significant effects. The results suggest that neuroticism should be considered a moderating factor in assessing anticipatory stress using surface electromyography at the trapezius muscle.
\end{abstract}

Keywords: surface electromyography, unpredictable threat, electric shock, personality dimension, mental stress assessment

Mental stress as a response to a stressor can have many short- and long-term implications for human beings. On the one hand, mental stress triggers acute physiological responses and may affectively influence behavior, mood, and well-being. On the other, chronic mental stress is associated with cardiovascular and musculoskeletal complaints or mental disorders (Esler, 2017; Lundberg, 2002; Schneiderman et al., 2005). In particular, work-related mental stress counts as a risk factor for various health problems, including musculoskeletal disorders, leading to incapacity for work and early retirement (Harvey et al., 2017). Several environmental and organizational exposure factors at the workplace, such as time pressure or high workloads, are identified as workplace stressors (Chamoux et al., 2018), which usually occur repeatedly over a long period of time and are perceived with low to moderate intensity of mental stress (Darvishi et al., 2016; Lowndes et al., 2018). From this perspective, it would be beneficial to objectively quantify mental stress by acquiring the acute physiological response to workplace stressors before, during, or after particular work tasks to develop concepts at the workplace to avoid negative consequences of mental stress.

As measured by surface electromyography (sEMG), the muscle response appears sensitive to various mental stress paradigms. Driven by the assumption that musculoskeletal complaints at the neck and shoulder could be caused by mental stress, many studies have investigated the activity of the trapezius muscle at monitor-based workplaces. These studies showed that several muscles are sensitive to mental stress caused by cognitive or psychosocial demands in the sense of increased muscle activity (Eijckelhof et al., 2013; Lundberg et al., 2002; Shahidi et al., 2013). Therefore, the application of sEMG might prove useful in identifying mental stress at the workplace. However, sEMG is rarely used in conjunction with anticipatory stress, potentially triggering feed-forward controlled stress responses (Del Giudice et al., 2018; Ursin \& Eriksen, 2010). At the workplace, anticipatory stress can be related to an important presentation or the evaluation of the working performance by a supervisor in the future. For this particular 
type of mental stress, it is unclear whether the muscle response changes after repeated exposure and how long recovery reactions would take. Further, since the upper trapezius muscle is rather sensitive to external disturbances, for example, movement artifacts, it may be helpful to identify other muscle areas that are both sensitive to different manifestations of mental stress and less involved in movements of the upper body. Studies of facial expressions, for example, linked specific muscles with major emotions like anger, disgust, fear, happiness, sadness, and surprise (Chen et al., 2016; Ekman \& Oster, 1979). Borges et al. (2018) and Perkins et al. (2012) found that potential threat scenarios produce environmental scanning facial behavior that in turn could result in increased activation of the frontalis muscle to broaden the field of vision.

Furthermore, the muscle response to workplace stressors could be moderated by individual predispositions as assessed by personality dimensions. In their Five-Factor model of personality, Costa and McCrae (1987) described the personality dimension neuroticism as a tendency to experience negative, distressing emotions and to possess associated behavioral and cognitive traits. Research has shown that a higher level of neuroticism is related to a higher appraisal of negative affect (Penley \& Tomaka, 2002) or a modified sympathetic and hypothalamic-pituitary-adrenal reactivity (Lahey, 2009). In an experimental study, McCleery and Goodwin (2001) showed that among 28 young adults, lower neuroticism led to a stronger cortisol response after a combined dexamethasone-corticotropinreleasing hormone test than higher neuroticism. Another study observed a greater skin conductance response after an emotional attending task among subjects with higher neuroticism than lower neuroticism (Reynaud et al., 2012). In addition, the degree of neuroticism may affect the recovery time after mental stress and the physiological response during repeated exposures to a stressor (Hughes et al., 2011).

The primary objective of the present study was to determine the muscle response of the trapezius and frontalis muscles and the moderating role of neuroticism during the expectation of an unpredictable and potentially painful electric shock compared to the expectation of a pleasant audio signal and how this response changes in repeated exposure. We hypothesized that muscle activity increases during the expectation of the first electrical shock compared to the audio signal and that the increase is moderated by neuroticism. In case of increased muscle activity, we further expected an adaption effect with a decrease in muscle activity during the expectation of the second electric shock compared to the first electric shock. The secondary objective was to assess muscle activity during a four-minute recovery phase after the first expectation of the electric shock in the event of significant muscle response.
We expected a decrease during the recovery phase that could be impaired in the group with higher neuroticism.

\section{Materials and Methods}

\section{Subjects}

The estimated sample size of 60 subjects was used in this explorative study to investigate the research objectives. This sample size estimation was inspired by a previous study (Luijcks et al., 2014), which included 64 subjects and found increased muscle activity at the upper part of the trapezius muscle in response to the expectation of an electrical shock by using a similar mental stress paradigm in combination with a similar research question. We intended to have a balanced distribution of gender (males and females) and three age groups (18-34, 35-51, 52-67 years). Due to restrictions in time and resources, we recruited 53 eligible healthy subjects. Exclusion criteria were self-reported acute pain or complaints at the neck or shoulder area, neurological or psychological diseases, under 18 or over 67 years of age, and using medication including beta-blockers, analgesics, antipsychotics, antidepressants, anticonvulsants, or anxiolytics. All subjects received financial compensation. The study was approved by the local ethics committee of the Medical Faculty of the University of Tübingen (561/2016BO1) and was conducted according to the principles of the Declaration of Helsinki (version 2013, Fortaleza).

\section{Procedure}

E-mail distributors recruited subjects among personnel of the University Hospital and University of Tübingen (Germany), and personal contacts or via friends and relatives. Potential subjects were informed to avoid sports activities involving the upper body and alcohol consumption one day before the measurement, caffeine and cocoa consumption the day of measurement, and eating or drinking (except water) at least two hours before the measurement. All measurements took place during one appointment that lasted about two hours.

Before the experiment, eligible subjects gave their written informed consent and filled out the Big Five Inventory-SEOP (Gosling et al., 2003; see Neuroticism section). Afterward, they were prepared for the sEMG measures (see Surface Electromyography section). The measurements were carried out in a $4 \times 4 \mathrm{~m}$ noise-isolated room, in which light and temperature $\left(22-25^{\circ} \mathrm{C}\right)$ conditions were held constant. During the measurement, subjects were seated on a chair in front of a desk with a screen. Posture 
and position were individually adjusted to control for body height. The top edge of the screen was aligned to the eyes of the subjects. Subjects were instructed to find a comfortable sitting position. During the recordings, the subjects had to look at the screen, sit still, and place their hands on the desk with their palms turned upwards while their shoulders were relaxed. A room divider prevented visual contact between the subject and examiner, and experimental guidance was provided through a standardized slide show presented on a screen in front of the subjects (see Instructions to the Subjects section). After every slide, subjects had to confirm verbally that the information about the procedure was understood.

The experiment included three conditions in a predefined order: the first control condition without an electrical shock (NoShock), the second (Shock1), and the third condition (Shock2) with an electrical shock. During the NoShock condition, a pleasant audio signal, which was introduced to the subjects in advance, was used instead of the electrical shock. Shock 2 was a repetition of Shock1 with a one-minute break in between. Directly before each condition, subjects had to rate their mental stress (see Perceived Mental Stress section). For all three conditions, subjects were not informed about the exact time point of the stimulus (audio signal or electrical shock). Directly after NoShock and before the Shock1 and Shock2 conditions, the individual electrical stimulus to induce physical pain (pain threshold) was determined (see Electric Shocks section).

Each condition consisted of an expectation phase, a stimulus, and a recovery phase, as visualized in Figure 1. The duration of the expectation phase was $1 \mathrm{~min} 55 \mathrm{~s}$ for NoShock, 2 min 55 s for Shock1, and 2 min 25 s for Shock2. Different durations for the expectation phase were chosen to prevent subjects from anticipating the onset of the electrical shock. The expectation phase was subdivided into 3, 4 , or 5 periods of $30 \mathrm{~s}$ plus a final period of $25 \mathrm{~s}$ directly before the stimulus. During each period, the subjects observed a rectangle as displayed on the monitor in front of them filled with incremental steps of $5 \mathrm{~s}$ and were full after $25 \mathrm{~s}$, after which the filled rectangle remained visible for another $5 \mathrm{~s}$. The final period always ended after $25 \mathrm{~s}$ with the application of the audio signal or the electrical shock at the time when the completely filled rectangle appeared.

\section{Instructions to the Subjects}

Before the expectation phase, subjects were briefed that a computer program would trigger the stimulus once within the next $4 \mathrm{~min}$ at an unforeseeable moment, but only during the time span within which the rectangle was completely filled. For Shock1 and Shock2, subjects were informed that the intensity of the electrical shock would be randomly determined by the computer program and would lie somewhere between their sensation threshold and clearly above their pain threshold (see Electrical Shocks section). The subsequent recovery phase lasted $4 \mathrm{~min}$.

\section{Electrical Shocks}

The intensity of the electrical shock applied during Shock 1 and Shock 2 was individually determined based on equation 1.

Electrical shock $=$ pain threshold +0.25

$$
\times \text { (pain threshold }- \text { sensation threshold). }
$$

Equation 1 was adopted from previous literature studies (Luijcks et al., 2014; Vossen et al., 2011) and slightly modified to ensure that the electrical shock was experienced as painful but still acceptable.

A two-step process determined the sensation and pain thresholds. In the first step, electrical shocks were applied to start from $0 \mathrm{~mA}$ in incremental steps of $0.4 \mathrm{~mA}$ until the subject felt the shock. This point was defined as the sensation threshold. In the second step, electrical shocks were applied to start from the sensation threshold in incremental steps of $1.0 \mathrm{~mA}$ until the subject reported it was painful. This point was defined as the pain threshold. This procedure was performed twice, and the mean of both thresholds $(\mathrm{mA})$ was used in equation 1.

The electrical shocks were rectangle pulses of $2 \mathrm{~ms}$ duration applied by a constant current electro-stimulator (DS7A, Digitimer Ltd., UK) through $\mathrm{Ag} / \mathrm{AgCl}$ cup electrodes filled with conductive electrode paste (Ten2O, Weaver and Company, USA) that were placed at the distal phalanx of the index and middle finger of the nondominant hand using adhesive tape (Fixomull stretch, BSN medical, Germany).

\section{Surface Electromyography}

The skin was prepared with abrasive paste (Nuprep, Weaver and Company, USA) to improve signaling for the bipolar sEMG measurement. Disposable surface electrodes (H93SG, Covidien, Kendall, USA) with an active area of $15 \mathrm{~mm}$ diameter were placed with an inter-electrode distance of $25 \mathrm{~mm}$ parallel to the muscle fibers at three different muscles or muscle sections at the dominant half of the body. Positions were: (1) the upper part of the trapezius muscle with the midpoint between the 7th cervical vertebrae and the acromion (TRAP $\left.{ }_{\mathrm{UP}}\right)$, (2) the transition between the upper and middle part of the trapezius muscle with the midpoint between the 7th cervical vertebrae and the 


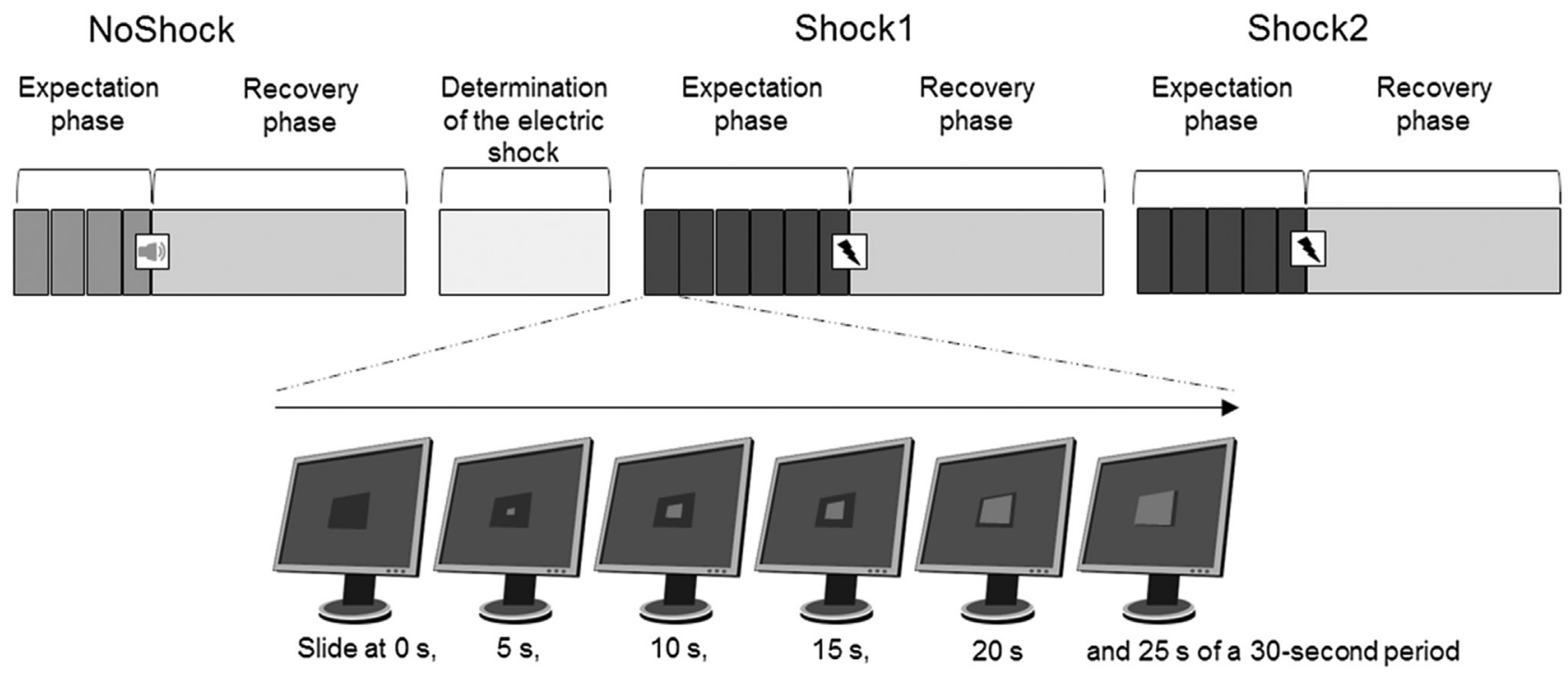

Figure 1. Measurement procedure showing the three conditions. Conditions: NoShock with audio signal, Shock1 with first electrical shock, and Shock2 with second electrical shock together with the determination of the individual stress stimulus and the slide show presenting the recurrently filling rectangles on the monitor during each period. Note that the subjects were not aware of the exact point in time when the stimulus (audio signal or electrical shock) would be applied.

superior angle of the scapula (TRAP $\mathrm{UP} / \mathrm{MID})$, and (3) the frontalis muscle with the outer edge of the lower electrode above the eyebrow on the vertical line through the midpoint of the eyes (FRONT). The ground electrode was placed at the 7 th cervical vertebrae.

The bipolar sEMG signals were differentially amplified, filtered (high pass filter, $2 \mathrm{nd}$ order, $-3 \mathrm{~dB}$ at $4 \mathrm{~Hz}$; low pass filter, 11th order, $-3 \mathrm{~dB}$ at $1,300 \mathrm{~Hz}$ ), sampled at $4,096 \mathrm{~Hz}$, analyzed, and stored using a combined data analyzer and logger (PS11-UD, THUMEDI GmbH \& Co. KG, Germany; overall CMRR > $96 \mathrm{~dB}$; the overall effective sum of noise $<0.8 \mu \mathrm{V}$ RMS; linearity typ. $\pm 0.15 \mathrm{~dB}$ at $25-1,100 \mathrm{~Hz}$ ). Data were real-time transformed by the device into the frequency domain (1,024-point Fast Fourier Transformation using a Bartlett-window with 50\% overlap) and digitally filtered (high-pass filter, 11th order, $-3 \mathrm{~dB}$ at $80 \mathrm{~Hz}$ to avoid interference from heart frequencies and motion artifacts). Powerline interference $(50 \mathrm{~Hz}$ and its first seven harmonics) was removed by replacing it with the spectral values of a $4-\mathrm{Hz}$ wide band around its center frequency using both spectral neighbors. The root-mean-square of the electrical activity $(\mathrm{EA}[\mu \mathrm{V}])$ was real-time calculated (375 ms moving window with $50 \%$ overlap) from the power spectrum and stored synchronously to the raw data by the PS11-UD device. The recorded EA was processed with custom-made software (SABCOM, Institute of Occupational and Social Medicine and Health Services Research, University Hospital Tübingen, Germany). The EA time series of each subject was screened for inconsistencies. If inconsistencies were suspected, photos synchronously taken every $2 \mathrm{~s}$ throughout the measurement were used to verify whether this could be related to violations of the procedure requirements (i.e., closed eyes, speaking, or apparent body movements). Sequences of the EA signal affected by violations of the measurement procedure were excluded, and $0.5 \mathrm{~s}$ before and after applying the electrical shock or the audio signal.

After visual inspection of the EA signals, the EA was normalized to a reference voluntary electrical activity $\left(\mathrm{EA}_{\mathrm{RVE}}\right.$ [1]). Reference voluntary electrical activities were determined during submaximal isometric muscle contractions lasting about $15 \mathrm{~s}$, of which the most stable $10 \mathrm{~s}$ were used to calculate the median EA. Subjects were asked to abduct their arms to $60^{\circ}$ in the scapular plane for the trapezius muscle and open their eyes as wide as possible by lifting the eyebrows for the frontalis muscle.

The average of the normalized EA of selected periods (Table 1) was calculated for each condition. The two periods of the expectation phase were chosen to account for a possible increase or decrease in muscle response over time. The study by Luijcks et al. (2014) investigated a recovery phase of only $2 \mathrm{~min}$. Therefore, we decided to apply a recovery phase of 4 min divided into four periods to find out whether the suggested decrease in muscle activity continued after $2 \mathrm{~min}$.

\section{Perceived Mental Stress}

Subjects rated their perceived mental stress on an 11-point numeric rating scale immediately before the start of each condition by answering the following question that was displayed on the monitor: "How would you rate your current mental tension on a scale from 0 to 10 , when 0 means 
Table 1. Selected periods from the time course for analysis

\begin{tabular}{|c|c|c|}
\hline Phase & Period & Abbreviation \\
\hline \multirow[t]{2}{*}{ Expectation phase } & First $30 \mathrm{~s}$ of expectation phase & EP1 \\
\hline & Last $25 \mathrm{~s}$ of expectation phase & EP2 \\
\hline \multirow[t]{4}{*}{ Recovery phase } & First $30 \mathrm{~s}$ of recovery phase & RP1 \\
\hline & $30 \mathrm{~s}$ between 120 and $150 \mathrm{~s}$ of recovery phase & RP2 \\
\hline & $30 \mathrm{~s}$ between 150 and $180 \mathrm{~s}$ of recovery phase & RP3 \\
\hline & Last $30 \mathrm{~s}$ of recovery phase & RP4 \\
\hline
\end{tabular}

no mental tension and 10 the highest imaginable mental tension?". Perceived mental stress was assessed as a subjective measure of a stress response to verify the current paradigm of mental stress.

\section{Neuroticism}

Subjects rated their personality dimension neuroticism by answering the Big Five Inventory-SEOP (Gosling et al., 2003; Schupp \& Gerlitz, 2014). Based on the construction of three questions, the mean score ranged from 1 to 7 for every subject. Internal consistency of neuroticism was acceptable with a Cronbach's $\alpha$ level of .779 in the present sample. If subjects rated neuroticism lower than or equal to the median of the overall distribution found in our study sample, they were allocated to the lower-neuroticism group. For values higher than the median, subjects were allocated to the higher-neuroticism group.

\section{Statistical Analyses}

\section{Presence of Mental Stress}

To confirm the presence of mental stress, two-factor mixed analysis of variance (ANOVA) was applied to the mental stress ratings, with condition (3 levels) as the within-subject factor and neuroticism (2 levels) as the between-subject factor. Additionally, $\mathrm{EA}_{\mathrm{RVE}}$ during the expectation phase (mean of EP1 and EP2) was correlated with the ratings of perceived mental stress before the Shock1 condition using the Spearman rank correlation $r_{\mathrm{s}}$ to clarify whether a significant muscle response matched the perception of mental stress.

\section{Primary Objectives}

To assess whether a possible muscle response to the anticipated stressor and its repetition depends on the personality dimension neuroticism, two-factor mixed ANOVA with the within-subject factor condition (3 levels) and the between-subject factor neuroticism (2 levels) was applied to the dependent variables of muscle activity (TRAP $_{\mathrm{UP}}$, TRAP $_{\mathrm{UP} / \mathrm{MID}}$, and FRONT) during the expectation phase (mean of EP1 and EP2). Since the muscle activity was not normally distributed, it was logarithmized ( $\left(n E A_{\mathrm{RVE}}\right)$.
Further, the assumption of homogeneity of variance was violated, and an explorative approach was chosen. Separately for each neuroticism group, single-factor repeated measures ANOVAs were applied to the dependent variables of the muscle activity with the within-subject factor condition (3 levels).

\section{Secondary Objective}

To assess the recovery effects after a muscle response, single-factor repeated measures ANOVAs were performed for the dependent variables of the muscle activity within each neuroticism group if post hoc analyses revealed a significant difference between the conditions NoShock and Shock1. The periods of the recovery phase (4 levels: RP1, $\mathrm{RP2}$, RP3, RP4) served as the within-subject factor time. Since the muscle activity was not normally distributed, it was logarithmized.

Before the ANOVAs, all dependent variables were checked visually for normal distribution, sphericity using Mauchly's sphericity test and, if necessary, for the assumption of homogeneity of variances using Levene's test. The standardized partial eta squared $\left(\eta_{\mathrm{p}}{ }^{2}\right)$ was calculated for the main and interaction effects of the ANOVAs. Post hoc analyses were performed using Tukey's honestly significant difference tests. The level of significance was set at $\alpha=.05$. The statistical analyses were carried out using SPSS 26 (IBM, USA) and JMP 13 (SAS Inc., USA).

\section{Results}

Of the 53 recruited subjects, two dropped out due to discomfort, and four were excluded retrospectively: two due to protocol violations and two due to signal interference. Thus, the final dataset included 47 subjects $(28$ women and $19 \mathrm{men}$; age $34 \pm 14$ years, height $174 \pm 10 \mathrm{~cm}$, weight $70 \pm 14 \mathrm{~kg})$.

\section{Presence of Mental Stress}

The result of the two-factor mixed ANOVA applied to the mental stress ratings showed a significant main effect of 


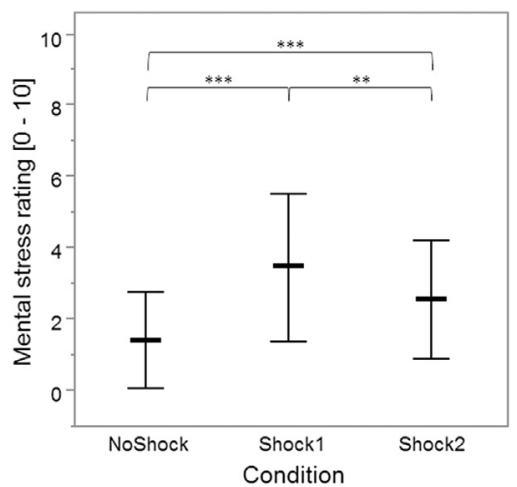

Figure 2. Perceived mental stress before the expectation phase. Conditions: NoShock with audio signal, Shock1 with first electrical shock, and Shock2 with second electrical shock; visualized in means and standard deviations of the mental stress ratings; significant $p$ values of post hoc comparisons: ${ }^{\star} p<.05 ;{ }^{* \star} p<.01$; ${ }^{* \star} p<.001$.

condition $\left[F(1.6,74.0)=28.5, p<.001, \eta_{\mathrm{p}}{ }^{2}=.39\right]$, but not of neuroticism $\left[F(1.0,45.0)=0.5, p=.505, \eta_{\mathrm{p}}{ }^{2}=.01\right]$, and there was no significant interaction between condition and neuroticism $\left[F(1.6,74.0)=0.3, p=.690, \eta_{\mathrm{p}}{ }^{2}=.01\right]$. Post hoc comparisons of the main effect of condition revealed a significantly higher mental stress rating directly before the expectation phase of Shock1 versus NoShock $(p<$ .001) and Shock2 $(p=.006)$. In addition, the mental stress rating before the Shock 2 condition was significantly higher than before NoShock $(p<.001$; Figure 2$)$.

The mental stress rating before the expectation phase of Shock1 and the muscle activities during the subsequent expectation phase did not correlate $\left(\mathrm{TRAP}_{\mathrm{UP}}: r_{\mathrm{s}}=\right.$ $-0.067, p=.653$; TRAP ${ }_{\mathrm{UP} / \mathrm{MID}}: r_{\mathrm{s}}=0.008, p=.960$; FRONT: $\left.r_{\mathrm{s}}=-0.076, p=.611\right)$.

\section{Primary Objectives}

After the total sample was separated using a median split of neuroticism at a score of 3.3, lower and higher neuroticism groups were characterized by the anthropometric data in Table 2.

The single-factor repeated measures ANOVAs indicated significant main effects of condition, but only within the higher neuroticism group for the muscle activity of TRAP ${ }_{U P}$

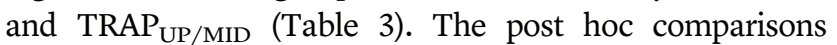
showed higher muscle activity in both muscles during Shock1 versus NoShock TRAP $_{\text {UP }} p<.001$; TRAP UP/MID $p<.001)$ or Shock2 (TRAP ${ }_{\mathrm{UP}} p=.004$ TRAP $_{\mathrm{UP} / \mathrm{MID}} p<$ .001) conditions, but not between NoShock and Shock2 (TRAP $_{\mathrm{UP}} p=.503$; $\left.\mathrm{TRAP}_{\mathrm{UP} / \mathrm{MID}} p=.995\right)$ conditions (Figure 3).

\section{Secondary Objective}

As a significant muscle response was found in the primary analysis for the group with higher neuroticism, two singlefactor repeated measure ANOVAs were applied to the muscle activity of $\mathrm{TRAP}_{\mathrm{UP}}$ and $\mathrm{TRAP}_{\mathrm{UP} / \mathrm{MID}}$ during the recovery phase of the Shock1 condition for this group. Subsequently, a significant main effect of time was found for the muscle activity of TRAP $\mathrm{UP} / \mathrm{MID}\left[F(1.3,27.5)=6.5, p=.011, \eta_{\mathrm{p}}{ }^{2}=\right.$ $.24]$, but not for $\operatorname{TRAP}_{\mathrm{UP}}\left[F(1.6,33.1)=2.8, p=.090, \eta_{\mathrm{p}}^{2}\right.$ $=.12$ ]. The post hoc comparisons for $\mathrm{TRAP}_{\mathrm{UP} / \mathrm{MID}}$ showed significantly higher muscle activity during RP1 compared to RP2 ( $p=.033), \mathrm{RP3}(p=.001)$, and RP4 ( $p=.004$, Figure 3).

\section{Discussion}

In the present study, an anticipatory stress paradigm that contained elements of unpredictability about a potentially painful threat in the form of an electrical shock was chosen to provoke a muscle response of the trapezius and the frontalis muscles. The neuroticism dimension of a short version of the Big Five Inventory included neuroticism as a potentially important personal modifying factor in the model. The primary objectives of this study were to investigate the moderating role of the personality dimension neuroticism on potentially elevated muscle activity at two parts of the trapezius muscle and the frontalis muscle during the expectation of an initial electrical shock, as well as possible adaptation effects of the muscle response when the mental stress paradigm was experienced for the second time. The second objective was to investigate the recovery phase after the first application of the electrical shock and the influence of neuroticism. The research paradigm of provoking anticipatory stress seemed to be fulfilled since low to moderate perceived mental stress was reported in the subjective evaluations.

Since the statistical prerequisite of homogeneity of variances was not fulfilled for the planned mixed ANOVAs,

Table 2. Anthropometric characteristics of groups with higher and lower neuroticism

\begin{tabular}{lccccc}
\hline Group & $n$ (female/male) & Neuroticism & Age [years] & Height [cm] & Weight $[\mathrm{kg}]$ \\
\hline Lower neuroticism & $25(14 / 11)$ & $2.5(0.6)$ & $37(13)$ & $177(10)$ & $74(13)$ \\
Higher neuroticism & $22(17 / 5)$ & $4.5(0.8)$ & $32(16)$ & $171(9)$ & $66(15)$ \\
\hline
\end{tabular}

Note. Means and standard deviation (SD) in brackets for neuroticism, age, height, and weight. 
Table 3. Results of the single-factor repeated measures ANOVAs of muscle activity within the lower and higher neuroticism group

\begin{tabular}{|c|c|c|c|c|c|}
\hline Muscle activity & Neuroticism group $(n)$ & $d f, d f$ residuals & $F$-value & $p$-value & $\overline{\eta_{p}{ }^{2}}$ \\
\hline \multirow[t]{2}{*}{$\overline{\text { TRAP UP }_{\text {uP }}}$} & Lower (25) & $2.0,48.0$ & 1.7 & .065 & .07 \\
\hline & Higher (22) & $2.0,42.0$ & 11.0 & $<.001 * * *$ & .34 \\
\hline \multirow[t]{2}{*}{ TRAPUP/MID } & Lower (25) & $1.5,35.8^{a}$ & 1.0 & .345 & .04 \\
\hline & Higher (22) & $2.0,42.0$ & 14.1 & $<.001 * * *$ & .40 \\
\hline \multirow[t]{2}{*}{ FRONT } & Lower (25) & $2.0,48.0$ & 2.0 & .148 & .08 \\
\hline & Higher (22) & $1.4,28.8^{a}$ & 1.3 & .281 & .06 \\
\hline
\end{tabular}

Note. Muscle activity (of the upper trapezius muscle: TRAPup, upper/middle trapezius muscle: TRAPUP/MID, and frontalis muscle: FRONT) based on natural logarithm of the normalized electrical activity (InEA $A_{R V E}$ ) during the first $30 \mathrm{~s}$ and the last $25 \mathrm{~s}$ of the expectation phase measured by surface electromyography; ${ }^{a}$ corrected for violation of sphericity via Greenhouse-Geisser adjustment; significant $p$-value: ${ }^{\star} p<.05 ;{ }^{*} p<.01 ;{ }^{* \star *} p<.001$.

single-factor repeated measures ANOVAs were used separately for the two neuroticism groups. Consequently, a potentially moderating influence of neuroticism on the muscle response to the present stress paradigm could not be statistically proven. However, in contrast to the frontalis muscle, where significant effects of the expectation of an electrical shock were absent, the muscle activity of the trapezius muscle showed a significant response during the first expectation phase, but only in the group with higher neuroticism. Additionally, during the four-minute recovery phase, the muscle activity of the upper/middle part of the trapezius muscle decreased not further after $180 \mathrm{~s}$. These findings align with the current literature, which suggests that neuroticism can modify physiological reactivity during mental stress. However, results from the literature are not entirely conclusive about a positive linear relation between the physiological response during mental stress and the level of neuroticism (Lahey, 2009).

One aspect that may have contributed to the trapezius muscle response of the group with higher neuroticism is that in the present study, the mental stress paradigm of anticipatory stress focused on the expectations of a stressor (electrical shock) as well as on the expectation of possible aversive effects of the stressor (pain). Since neuroticism is associated with increased sensitivity to threats and susceptibility to negative thoughts and emotions (Perkins et al., 2015), a more negative appraisal of the stressor could have lowered the threshold for response triggered. Further, elements of unpredictability in a threat scenario can trigger emotional responses with feelings of anxiety (Grillon et al., 2004; Grupe \& Nitschke, 2013; Tracy et al., 2017). Since individuals with higher neuroticism are more likely to experience feelings of anxiety (Kendler et al., 2004), it is possible that the emotional processing of anxiety may have influenced a behavioral response, and that may explain the differences between groups (Li et al., 2019).

Interestingly, despite elevated muscle activity within the group with higher neuroticism during Shock1, there were no correlations to the perceived mental stress. A discrepancy between perceived mental stress and the corresponding physiological response was also found by Campbell and Ehlert (2012) and emphasized the advantage of using additional objective methods in the context of a mental stress assessment.

Furthermore, both parts of the trapezius muscle showed an adaptation effect during the expectation of the second electrical shock within the group with higher neuroticism, indicated by reduced muscle activity. In contrast, Willmann et al. (2012) found no adaption effects of the upper trapezius muscle during a Stroop color word test in healthy subjects. However, they related their findings to a high attentional load during the test, which plays a subordinate role in the present mental stress paradigm.

The lower neuroticism group showed no significantly increased muscle activity of the trapezius muscle during the expectation of an electrical shock. Consequently, no adaptation effects were observed at the second exposure to the same anticipatory stress or subsequent recovery phases. Given a mean value of 2.6 for the personality dimension neuroticism in a sample representative of the German population, the median value of 2.5 cannot be interpreted as low (Bluml et al., 2013), and shows that there is most likely no bias in the present study sample towards a low level of neuroticism.

However, previous research reported elevated muscle activity at the upper part of the trapezius muscle in response to a comparable anticipatory stress paradigm (Luijcks et al., 2014, 2016), without distinguishing between higher and lower neuroticism. These studies used a continuous three-minute period, during which the electrical shock was potentially applied, while the effective expectation-time in the present study accumulated up to $25 \mathrm{~s}$ (Shock1) and $20 \mathrm{~s}$ (Shock2), respectively, and may account for weakened mental stress. Nonetheless, the mental stress ratings collected directly before the shock conditions were comparable to those mentioned by Luijcks et al. (2014) (on mean 3.6). Another difference concerns the instructions given to the subjects during the expectation phases. In the current study, subjects tracked a rectangle on a screen, whereas Luijcks et al. (2014) reported that subjects only had to keep 

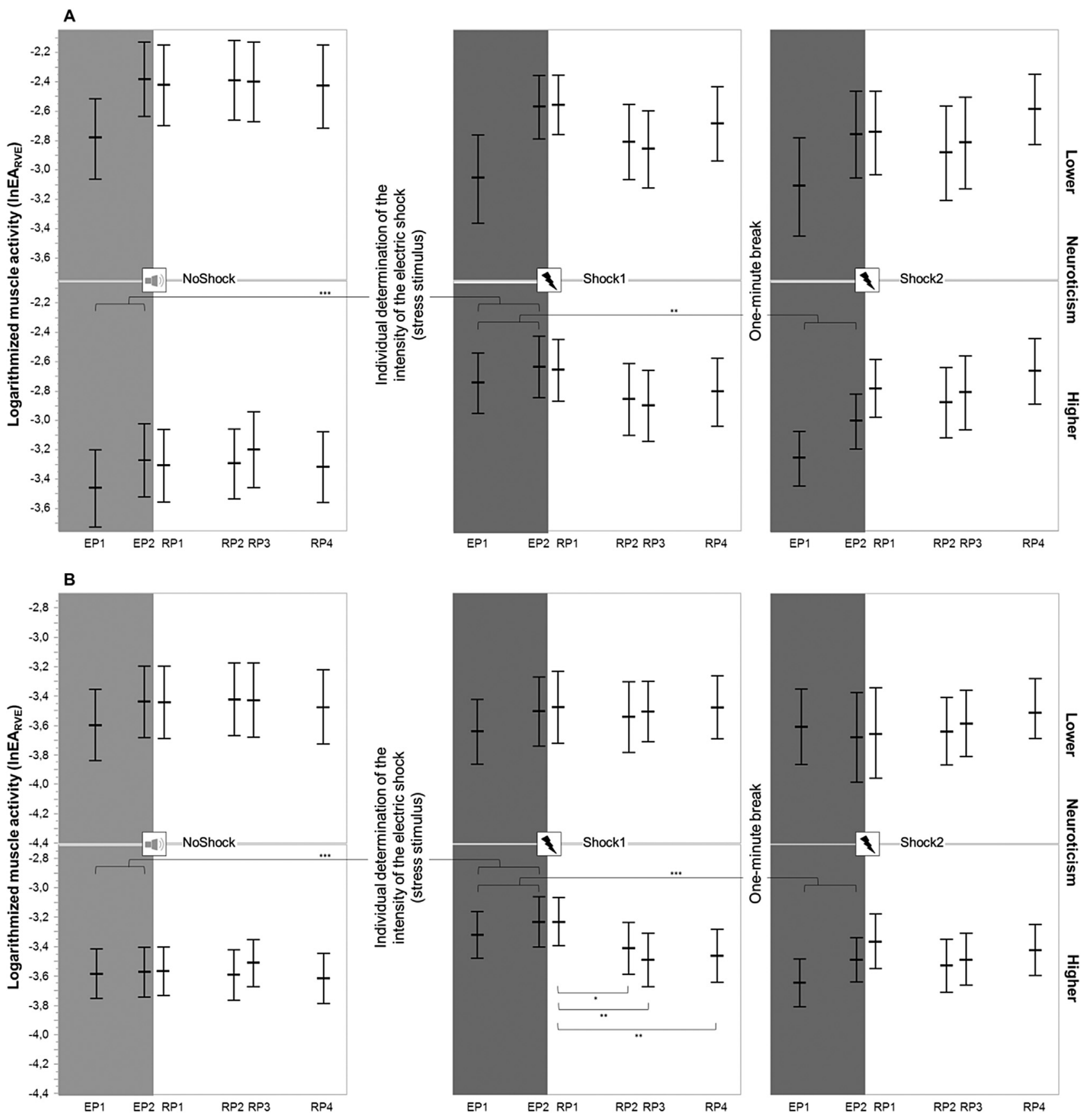

Figure 3. Periods of muscle activity of the upper trapezius muscle (A) and the upper/middle trapezius muscle (B). Periods: EP1 as first $30 \mathrm{~s}$ of expectation phase, EP2 as last $25 \mathrm{~s}$ of expectation phase, RP1 as first $30 \mathrm{~s}$ of recovery phase, RP2 as $30 \mathrm{~s}$ between 120 and $150 \mathrm{~s}$ of recovery phase, RP3 as 30 s between 150 and 180 s of recovery phase, RP4 as last 30 s of recovery phase; conditions: NoShock with audio signal, Shock1 with first electrical shock: and Shock2 with second electrical shock; visualized in means and standard errors of natural logarithmic muscle activity measured by surface electromyography (InEA RVE); significant $p$-values of post hoc comparisons: ${ }^{\star} p<.05 ;{ }^{\star *} p<.01 ;{ }^{* *} p<.001$.

their eyes open. Therefore, it is possible that effects on muscle activity were masked by the effects of the visual demands (Richter et al., 2010; Zetterberg et al., 2013).

Moreover, there are several studies showing associations between various mental stress paradigms and elevated muscle activity at different parts of the body (Krantz et al., 2004; Lundberg et al., 1994, 2002; Nilsen et al.,
2007; Westgaard et al., 2013; Woda et al., 2013). However, a notable difference to the present study with respect to the anticipatory stress paradigm should be mentioned. In the present study, subjects were positioned in a resting posture, while subjects in the aforementioned studies were involved in tasks requiring cognitive and motor activities, such as the Trier Social Stress Test, arithmetic calculations, or the 
Stroop color word test. In these studies, cognitive tasks were combined with executive functions, which were accompanied by elements of social assessment. The social assessment can lead to additional psychosocial stress, which may account for a stronger physiological response (Dickerson \& Kemeny, 2004). Supporting this hypothesis, D'Attilio et al. (2013), for example, presented emotionally affective pictures while subjects were standing comfortably and were not involved in cognitive or motor tasks. Their results indicated no differences in sEMG amplitudes between neutral, pleasant, or unpleasant pictures at the upper part of the trapezius muscle and some facial muscles.

A limitation of this study may be attributed to "invisible" postural changes during the measurement procedure. Postural changes were assessed visually by screening pictures of the subjects for violations of the procedure requirements. However, it cannot fully be ruled out that slight head movements or variations of the angle between upper and forearm caused variability in the activity at the trapezius muscle across and within conditions (Goncalves et al., 2017), especially when considering low levels of muscle activity at the trapezius muscle (total mean and standard deviation of the non-normalized EA of TRAP $_{\mathrm{UP}} 2.91 \pm$ 3.98 and $\mathrm{TRAP}_{\mathrm{UP} / \mathrm{MID}} 2.36 \pm 2.26 \mu \mathrm{V}$ ).

The difference between the gender ratios in lower and higher neuroticism groups seems to indicate that the personality dimension neuroticism is more emphasized in women, which is supported by literature (Costa et al., 2001). Therefore, the different responses of the muscle activity of the trapezius muscle of the two groups could reflect a different physiological response during mental stress of men and women, due to sex-specific brain anatomy or hormonal status (Novais et al., 2017). Juster et al. (2016), for example, found similar cortisol responses to the Trier Social Stress Test in women and men after adjusting for sex hormone, and Childs et al. (2010) showed that women in the luteal phase of the menstrual cycle had a stronger heart rate response to the Trier Social Stress Test than women in the follicular phase.

It should be noted that the generalizability of the selected paradigm regarding anticipatory stress in the workplace is limited. On the one hand, this results from the threat scenario of anticipated pain due to the expectation of an electric shock, which can hardly be found in the working environment. On the other hand, the subjects were asked to sit still without any possibility to avoid or mitigate the anticipated consequences of the stressor by their own actions. Accordingly, both existing paradigms, such as the Trier Social Stress Test (Kirschbaum et al., 1993) and newly developed paradigms that allow for a more realistic approach to real scenarios in the working environment would have to be considered for better generalizability in further studies.

\section{Conclusion}

The analysis of the present study showed in two groups, with lower and higher neuroticism, different responses of the trapezius muscle during anticipatory stress. However, this applies not to the frontalis muscle, which seems not to respond to the present mental stress paradigm. In particular, the post hoc analysis showed elevated muscle activity of the trapezius muscle in the higher neuroticism group during the expectation of the first electrical shock, which may point towards a more unambiguous muscle response when neuroticism is considered as a personality dimension in the analysis. The personality dimension of neuroticism should be considered, especially in future studies that use sEMG of the trapezius muscle to investigate the anticipation of stressors, as this might allow for a more differentiated and objective risk assessment of mental stress in the workplace.

\section{References}

Bluml, V., Kapusta, N. D., Doering, S., Brahler, E., Wagner, B., \& Kersting, A. (2013). Personality factors and suicide risk in a representative sample of the German general population. PLoS One, 8(10), Article e76646. https://doi.org/10.1371/journal. pone.0076646

Borges, V. F., Ferrer-Rosa, N. M., Juruena, M. F., \& Estanislau, C. (2018). Recognition of a response to potential threat: Evidence for a facial expression of anxiety? Psychology \& Neuroscience, 11(1), 18-27. https://doi.org/10.1037/pne0000116

Campbell, J., \& Ehlert, U. (2012). Acute psychosocial stress: Does the emotional stress response correspond with physiological responses? Psychoneuroendocrinology, 37(8), 1111-1134. https://doi.org/10.1016/j.psyneuen.2011.12.010

Chamoux, A., Lambert, C., Vilmant, A., Lanhers, C., Agius, R., Boutaleb, M., Bonneterre, V., Naughton, G., Pereira, B., Djeriri, K., Ben-Brik, E., Breton, C., De Clavière, C., Letheux, C., Paolillo, A. G., Valenty, M., Vandenberghe, O., Aeschlimann, M. P., Lasfargues, G., ... Dutheil, F. (2018). Occupational exposure factors for mental and behavioral disorders at work: The FOREC thesaurus. PLoS One, 13(6), Article e0198719. https://doi.org/10.1371/journal.pone.0198719

Chen, Y. M., Yang, Z. L., \& Wang, J. P. (2016). Eyebrow emotional expression recognition using surface EMG signals (vol 168, pg 871, 2015). Neurocomputing, 177, 671-671. https://doi.org/ 10.1016/j.neucom.2015.12.059

Childs, E., Dlugos, A., \& De Wit, H. (2010). Cardiovascular, hormonal, and emotional responses to the TSST in relation to sex and menstrual cycle phase. Psychophysiology, 47(3), 550559. https://doi.org/10.1111/j.1469-8986.2009.00961.x

Costa, P. T., \& McCrae, R. R. (1987). Neuroticism, somatic complaints, and disease: Is the bark worse than the bite? Journal of Personality, 55(2), 299-316. https://doi.org/10.1111/j.14676494.1987.tb00438.x

Costa, P. T., Terracciano, A., \& McCrae, R. R. (2001). Gender differences in personality traits across cultures: Robust and surprising findings. Journal of Personality and Social Psychology, 81(2), 322-331. https://doi.org/10.1037/0022-3514. 81.2.322 
D’Attilio, M., Rodolfino, D., Saccucci, M., Abate, M., Romani, G. L., Festa, F., \& Merla, A. (2013). Effects of viewing affective pictures on sEMG activity of masticatory and postural muscles. Neuroscience Letters, 544, 10-14. https://doi.org/10.1016/j. neulet.2013.02.053

Darvishi, E., Maleki, A., Giahi, O., \& Akbarzadeh, A. (2016). Subjective mental workload and its correlation with musculoskeletal disorders in bank staff. Journal of Manipulative and Physiological Therapeutics, 39(6), 420-426. https://doi.org/ 10.1016/j.jmpt.2016.05.003

Del Giudice, M., Buck, C. L., Chaby, L. E., Gormally, B. M., Taff, C. C., Thawley, C. J., Vitousek, M. N., \& Wada, H. (2018). What is stress? A systems perspective. Integrative and Comparative Biology, 58(6), 1019-1032. https://doi.org/10.1093/icb/icy114

Dickerson, S. S., \& Kemeny, M. E. (2004). Acute stressors and cortisol responses: A theoretical integration and synthesis of laboratory research. Psychological Bulletin, 130(3), 355-391. https://doi.org/10.1037/0033-2909.130.3.355

Eijckelhof, B. H., Huysmans, M. A., Bruno Garza, J. L., Blatter, B. M., van Dieen, J. H., Dennerlein, J. T., \& van der Beek, A. J. (2013). The effects of workplace stressors on muscle activity in the neck-shoulder and forearm muscles during computer work: A systematic review and meta-analysis. European Journal of Applied Physiology, 113(12), 2897-2912. https://doi.org/ 10.1007/s00421-013-2602-2

Ekman, P., \& Oster, H. (1979). Facial expressions of emotion. Annual Review of Psychology, 30, 527-554. https://doi.org/ 10.1146/annurev.ps.30.020179.002523

Esler, M. (2017). Mental stress and human cardiovascular disease. Neuroscience \& Biobehavioral Reviews, 74(Pt B), 269-276. https://doi.org/10.1016/j.neubiorev.2016.10.011

Goncalves, J. S., Shinohara Moriguchi, C., Takekawa, K. S., Coury, H., \& Sato, T. O. (2017). The effects of forearm support and shoulder posture on upper trapezius and anterior deltoid activity. The Journal of Physical Therapy Science, 29(5), 793798. https://doi.org/10.1589/jpts.29.793

Gosling, S. D., Rentfrow, P. J., \& Swann, W. B. (2003). A very brief measure of the Big-Five personality domains. Journal of Research in Personality, 37(6), 504-528. https://doi.org/ 10.1016/S0092-6566(03)00046-1

Grillon, C., Baas, J. P., Lissek, S., Smith, K., \& Milstein, J. (2004). Anxious responses to predictable and unpredictable aversive events. Behavioral Neuroscience, 118(5), 916-924. https://doi. org/10.1037/0735-7044.118.5.916

Grupe, D. W., \& Nitschke, J. B. (2013). Uncertainty and anticipation in anxiety: An integrated neurobiological and psychological perspective. Nature Reviews Neuroscience, 14(7), 488-501. https://doi.org/10.1038/nrn3524

Harvey, S. B., Modini, M., Joyce, S., Milligan-Saville, J. S., Tan, L., Mykletun, A., Bryant, R. A., Christensen, H., \& Mitchell, P. B. (2017). Can work make you mentally ill? A systematic metareview of work-related risk factors for common mental health problems. Occupational and Environmental Medicine, 74(4), 301-310. https://doi.org/10.1136/oemed-2016-104015

Hughes, B. M., Howard, S., James, J. E., \& Higgins, N. M. (2011). Individual differences in adaptation of cardiovascular responses to stress. Biological Psychology, 86(2), 129-136. https://doi.org/10.1016/j.biopsycho.2010.03.015

Juster, R. P., Raymond, C., Desrochers, A. B., Bourdon, O., Durand, N., Wan, N., Puessner, J. C, \& Lupien, S. J. (2016). Sex hormones adjust "sex-specific" reactive and diurnal cortisol profiles. Psychoneuroendocrinology, 63, 282-290. https://doi. org/10.1016/j.psyneuen.2015.10.012

Kendler, K. S., Kuhn, J., \& Prescott, C. A. (2004). The interrelationship of neuroticism, sex, and stressful life events in the prediction of episodes of major depression. American Journal of Psychiatry, 161(4), 631-636. https://doi.org/10.1176/appi. ajp.161.4.631

Kirschbaum, C., Pirke, K. M., \& Hellhammer, D. H. (1993). The "Trier Social Stress Test" - a tool for investigating psychobiological stress responses in a laboratory setting. Neuropsychobiology, 28(1-2), 76-81. https://doi.org/10.1159/000119004

Krantz, G., Forsman, M., \& Lundberg, U. (2004). Consistency in physiological stress responses and electromyographic activity during induced stress exposure in women and men. Integrative Psychological and Behavioral Science, 39(2), 105-118. https:// doi.org/10.1007/bf02734276

Lahey, B. B. (2009). Public health significance of neuroticism. American Psychologist, 64(4), 241-256. https://doi.org/ 10.1037/a0015309

Li, X., Zhang, M., Li, K., Zou, F., Wang, Y., Wu, X., \& Zhang, H. (2019). The altered somatic brain network in state anxiety. Frontiers in Psychiatry, 10, Article 465. https://doi.org/10.3389/ fpsyt.2019.00465

Lowndes, B. R., Forsyth, K. L., Blocker, R. C., Dean, P. G., Truty, M. J., Heller, S. F., Blackmon, S., Hallbeck, M. S., \& Nelson, H. (2018). NASA-TLX assessment of surgeon workload variation across specialties. Annals of Surgery, 271(4), 686-692. https:// doi.org/10.1097/SLA.0000000000003058

Luijcks, R., Hermens, H. J., Bodar, L., Vossen, C. J., Van Os, J., \& Lousberg, R. (2014). Experimentally induced stress validated by EMG activity. PLoS One, 9(4), Article e95215. https://doi.org/ 10.1371/journal.pone.0095215

Luijcks, R., Vossen, C. J., Roggeveen, S., van Os, J., Hermens, H. J., \& Lousberg, R. (2016). Impact of early life adversity on EMG stress reactivity of the trapezius muscle. Medicine (Baltimore), 95(39), Article e4745. https://doi.org/10.1097/MD.0000000000004745

Lundberg, U. (2002). Psychophysiology of work: Stress, gender, endocrine response, and work-related upper extremity disorders. American Journal of Industrial Medicine, 41(5), 383-392. https://doi.org/10.1002/ajim.10038

Lundberg, U., Forsman, M., Zachau, G., Eklof, M., Palmerud, G., Melin, B., \& Kadefors, R. (2002). Effects of experimentally induced mental and physical stress on motor unit recruitment in the trapezius muscle. Work and Stress, 16(2), 166-178. https://doi.org/10.1080/02678370210136699

Lundberg, U., Kadefors, R., Melin, B., Palmerud, G., Hassmen, P., Engstrom, M., \& Dohns, I. E. (1994). Psychophysiological stress and EMG activity of the trapezius muscle. International Journal of Behavioral Medicine, 1(4), 354-370. https://doi.org/10.1207/ s15327558ijbm0104_5

McCleery, J. M., \& Goodwin, G. M. (2001). High and low neuroticism predict different cortisol responses to the combined dexamethasone - CRH Test. Biological Psychiatry, 49(5), 410415. https://doi.org/10.1016/s0006-3223(00)01056-8

Nilsen, K. B., Sand, T., Stovner, L. J., Leistad, R. B., \& Westgaard, R. H. (2007). Autonomic and muscular responses and recovery to one-hour laboratory mental stress in healthy subjects. BMC Musculoskeletal Disorders, 8, Article 81. https://doi.org/ 10.1186/1471-2474-8-81

Novais, A., Monteiro, S., Roque, S., Correia-Neves, M., \& Sousa, N. (2017). How age, sex and genotype shape the stress response. Neurobiology of Stress, 6, 44-56. https://doi.org/10.1016/j. ynstr.2016.11.004

Penley, J. A., \& Tomaka, J. (2002). Associations among the Big Five, emotional responses, and coping with acute stress. Personality and Individual Differences, 32(7), 1215-1228. https://doi.org/10.1016/S0191-8869(01)00087-3

Perkins, A. M., Arnone, D., Smallwood, J., \& Mobbs, D. (2015). Thinking too much: Self-generated thought as the engine of neuroticism. Trends in Cognitive Sciences, 19(9), 492-498. https://doi.org/10.1016/j.tics.2015.07.003 
Perkins, A. M., Inchley-Mort, S. L., Pickering, A. D., Corr, P. J., \& Burgess, A. P. (2012). A facial expression for anxiety. Journal of Personality and Social Psychology, 102(5), 910-924. https://doi. org/10.1037/a0026825

Reynaud, E., El Khoury-Malhame, M., Rossier, J., Blin, O., \& Khalfa, S. (2012). Neuroticism modifies psychophysiological responses to fearful films. PLoS One, 7(3), Article e32413. https://doi.org/10.1371/journal.pone.0032413

Richter, H. O., Banziger, T., Abdi, S., \& Forsman, M. (2010). Stabilization of gaze: A relationship between ciliary muscle contraction and trapezius muscle activity. Vision Research, 50 (23), 2559-2569. https://doi.org/10.1016/j.visres.2010.08.021

Schneiderman, N., Ironson, G., \& Siegel, S. D. (2005). Stress and health: Psychological, behavioral, and biological determinants. Annual Review of Clinical Psychology, 1, 607-628. https://doi. org/10.1146/annurev.clinpsy.1.102803.144141

Schupp, J., \& Gerlitz, J.-Y. (2014). Big Five Inventory-SOEP (BFI-S) (Publication no. 10.6102/zis54). https://zis.gesis.org/pdfFiles/ Dokumentation/Schupp+_Big_Five_Inventors_SOEP_(BFI-S).pdf

Shahidi, B., Haight, A., \& Maluf, K. (2013). Differential effects of mental concentration and acute psychosocial stress on cervical muscle activity and posture. Journal of Electromyography and Kinesiology, 23(5), 1082-1089. https://doi.org/10.1016/ j.jelekin.2013.05.009

Tracy, L. M., Gibson, S. J., Georgiou-Karistianis, N., \& Giummarra, M. J. (2017). Effects of explicit cueing and ambiguity on the anticipation and experience of a painful thermal stimulus. PLOS One, 12(8), Article e0183650. https://doi.org/10.1371/journal. pone.0183650

Ursin, H., \& Eriksen, H. R. (2010). Cognitive activation theory of stress (CATS). Neuroscience \& Biobehavioral Reviews, 34(6), 877-881. https://doi.org/10.1016/j.neubiorev.2009.03.001

Vossen, H. G. M., van Breukelen, G. J.P., van Os, J., Hermens, H. J., \& Lousberg, R. (2011). Association between event-related potentials and pain ratings not as straightforward as often thought. Journal of Psychophysiology, 25(1), 18-25. https://doi. org/10.1027/0269-8803/a000028

Westgaard, R. H., Mork, P. J., Loras, H. W., Riva, R., \& Lundberg, U. (2013). Trapezius activity of fibromyalgia patients is enhanced in stressful situations, but is similar to healthy controls in a quiet naturalistic setting: A case-control study. BMC Musculoskeletal Disorders, 14, Article 97. https://doi.org/10.1186/ 1471-2474-14-97

Willmann, M., Langlet, C., Hainaut, J. P., \& Bolmont, B. (2012). The time course of autonomic parameters and muscle tension during recovery following a moderate cognitive stressor: Dependency on trait anxiety level. International Journal of Psychophysiology, 84(1), 51-58. https://doi.org/10.1016/j. ijpsycho.2012.01.009
Woda, A., L'heveder, G., Ouchchane, L., \& Bodere, C. (2013). Effect of experimental stress in 2 different pain conditions affecting the facial muscles. Journal of Pain, 14(5), 455-466. https://doi. org/10.1016/j.jpain.2012.12.008

Zetterberg, C., Forsman, M., \& Richter, H. O. (2013). Effects of visually demanding near work on trapezius muscle activity. Journal of Electromyography and Kinesiology, 23(5), 1190-1198. https://doi.org/10.1016/j.jelekin.2013.06.003

\section{History}

Received March 20, 2020

Revision received November 27, 2020

Accepted September 1, 2021

Published online October 14, 2021

\section{Acknowledgments}

The authors would also like to gratefully acknowledge Timon Voll, Felix Epple, and Falko Riempp for help carrying out the measurements.

\section{Conflict of Interest}

The authors declare no potential conflicts of interest with respect to the research, authorship, and/or publication of this article.

\section{Open Data}

The data that support the findings of this study are available from the corresponding author, [Florestan Wagenblast], upon reasonable request.

\section{Funding}

Open access publication enabled by the University of Tübingen. The study was financed by the institute's own resources. The work of the Institute of Occupational and Social Medicine and Health Services Research is supported by an unrestricted grant of the Employers' Association of the Metal and Electric Industry BadenWürttemberg (Südwestmetall). In addition, FW received a personal grant (Stipendium "Arbeit und Gesundheit"), as the study is part of his doctoral research study.

\section{Florestan Wagenblast}

Institute of Occupational and Social Medicine and Health Services Research

University Hospital Tübingen

University of Tübingen

Wilhelmstraße 27

72074 Tübingen

Germany

florestan.wagenblast@med.uni-tuebingen.de 